\title{
Activity-Based Costing vs Theory of Constraints: An Empirical Study into Their Effect on the Cost Performance of NPD Initiatives
}

\author{
Zu'bi M. F. Al-Zu'bi ${ }^{1} \&$ Basheer Ahmad Khamees ${ }^{1}$ \\ ${ }^{1}$ School of Business, The University of Jordan, Amman, Jordan \\ Correspondence: Zu'bi M. F. Al-Zu'bi, School of Business, The University of Jordan, Amman, Jordan. Tel: 962- \\ 79-562-9397. E-mail: z.alzubi@ju.edu.jo
}

Received: November 3, 2014

Accepted: November 16, 2014 Online Published: November 25, 2014

doi:10.5539/ijef.v6n12p157

URL: http://dx.doi.org/10.5539/ijef.v6n12p157

\begin{abstract}
The aim of this paper is to provide empirical evidence about the effect of costing technique used by companies on the cost performance of new product development initiatives in industrial companies in Europe. A survey was carried out collecting response from 204 companies in the different consumer product industries to investigate the comparative effect of those two popular techniques. Statistical analyses revealed significant relationship with both $\mathrm{ABC}$ and TOC but with a much stronger effect of ABC on the NPD cost performance.
\end{abstract}

Keywords: activity based costing, theory of constraints, new product development

\section{Introduction}

Accounting is an information system that provides users, internal and external, with information they need to take decisions. The part of information that is developed to help managers within an organization is called management accounting. Management accounting depends on cost accounting in providing managers with information. Cost accounting is concerned with calculating the cost of production inputs. It should be clarified that management accounting and cost accounting is a single subject but the distinction between them arises as a result of the historical development of the subject and is increasingly a matter of academic interest only (Harper, 1995).

Traditionally, a product cost is the sum of direct materials cost, direct labour cost and manufacturing overhead cost, which is assigned to products based on an allocation base such as direct labour hours or machine hours. Using a single allocation base results in that costs are spread over products in a way that results in unreliable cost information. To overcome this problem, companies started in the late 1960s developing alternative methods to allocate costs. That was the beginnings of a theory in the academic literature. Nonetheless, it was until the 1980s when $\mathrm{ABC}$ became widely adopted. If it wasn't for the confluence of several factors, $\mathrm{ABC}$ would have remained a dead letter despite its attractiveness. These defining and important factors of $\mathrm{ABC}$ are strong competition, changing manufacturing methods and inexpensive information technology. On the other hand another technique was developed and that is the Theory of Constraints.

The theory of constraints is a five-step management philosophy/methodology that focuses on identifying and correcting the bottleneck of the process. The steps are identifying the constraint, exploiting it, altering the rest of the system to aid in the elimination of the bottleneck, improving the constraint and repeating the process. The bottleneck is the constraint that is responsible for the throughput volume of the system others see TOC as merely a decision making tool, but the majority consensus is that TOC is a short term management solution if you are seeking to eliminate on constraint (Ifandouldas \& Gurd, 2010), but it can also be seen as an on-going process where managers are constantly working to better there system by eliminating the changing constraint. Developed by Dr. Eliyahu M. Goldratt in the 1970s, the TOC recognizes that there will always be limitations or constraints on performance of the "system of interest" The constraint in the system can be physical, political or behavioral. However, in the following section we will see how both techniques has been historically used without careful consideration for the new product development processes and how the main question of this paper " How do activity based costing and theory of constraints costing techniques affect the cost performance of NPD initiatives?" 


\section{ABC Vs TOC:}

Activity based costing (ABC) has been extensively researched since it was first introduced in the mid-1980s as an alternative to more traditional costing systems that were becoming increasingly less relevant as pricing structures changed. Over the years $\mathrm{ABC}$ has been investigated from a number of different angels. In the mid to late-nineties many researchers focused on the variables that predict success for $\mathrm{ABC}$ implementation. Shields and Young $(1989,1994)$ posited that the most important variables are not technical and economic factors, as would normally be the case for technical innovations and had been widely assumed, but instead were organizational and behavioural factors normally associated with administrative changes. The most important variables they identified included support from higher-level management and connections between the $\mathrm{ABC}$ system and competitive strategies. This theory was tested more extensively by Shields in 1995 and led to empirical support for the initial hypothesis. A host of other studies have illustrated the influence of individual organizational and behavioural factors, including: company size (Gosselin, 1997; Armitage \& Ncholson, 1993; Innes et al., 2000), automation (Drury \& Tayles, 1994) the complexity of production processes and product diversity (Bjornenak, 1997), organizational culture (Friedman \& Lyne, 1999), stock market and firm performance (Gordon \& Silvester, 1999; Kennedy \& Affleck-Graves, 2001), institutional factors (Sisaye, 2003; Malmi, 1999; Armstrong, 2002; Jones \& Dugdale, 2002), and a variety of other behavioural factors (Shields, 1995; Foster \& Swenson, 1997; McGowan \& Klammer, 1997; Bhimani \& Pigott, 1992; Anderson, 1995; Anderson \& Young, 1999; Argyris \& Kaplan, 1994; Krumwiede, 1998; Bhimani et al., 2005).

In 1990, Cooper and Zmud researched the implementation of material requirements planning (MRP), by investigating each factor separately in each of the six stages of implementation originally introduced by Kwon and Zmud (1987): initiation, adoption, adaption, acceptance, reutilization and infusion. The study found that not all factors were equally important at all stages, a result that led Krumwiede (1998) to investigate whether the same may be true of the stages of $\mathrm{ABC}$ implementation. Krumwiede expanded the initial model to include 10 stages, and found that while, as research had previously shown, organizational and behavioural factors were critical, they were of more importance after the initial adoption, whereas technical factors were more influential in the original decision to adopt $\mathrm{ABC}$. Other studies have concurred with the finding that factors affect each stage of ABC implementation differently (Anderson, 1995; Gosselin, 1997). Babad and Balachandran (1993) believe that for $\mathrm{ABC}$ to be 'successful' in terms of implementation and performance, there needs to be a balance between costs and benefits, meaning that if there are too many cost drivers, planning and data collection costs can be prohibitive and expensive, therefore it is crucial to model the ABCM planning off of the optimal cost drivers.

Scholars have also looked at motivations for switching to ABC (Nassar et al., 2013; Al-Basteki \& Ramadan, 1998). Their research found that industrial firms in both Jordan and Bahrain were not implementing the ABC method because of confusion about the design and the implementation needs to be reworded with identifying the activities. The least difficulties with implementation was resistance to change, which showed that Middle Eastern industrial sector businesses were a good environment for changing their costing methods as long as they fully understood the concepts. Other important drivers for lack of implementation were confusion in explaining and selling the concept to employees and lack of understanding about $\mathrm{ABC}$ from production supervisors. There were no implementation difficulties where the firm's accountants' understanding of $\mathrm{ABC}$ was concerned, the increased workload because of data collection, and accountants' reluctance to changing the cost-system. The lack of implementation difficulties from increased workload did not agree with the studies of Green and Amenkhienan 1992; Cobb et al. 1992. (Al-Basteki \& Ramadan, 1998) proved that ABC implementation could work in developing nations; such as Bahrain and that some firms did not adopt the $\mathrm{ABC}$ method at all because they were satisfied with their current costing metrics. Nassar et al. (2013) also looked into the reasons why firms decided to implement $\mathrm{ABC}$ in the first place and it was found that it was because the method was "in fashion," followed by the fact that firms wanted to try new costing methods. The study also found that the most important actors in initiating change were to adequately train employees in understanding $\mathrm{ABC}$ and ensuring support and guidance from managers. Nassar et al. (2013) found that respondents were most concerned with implementation factors regarding increased overhead costs including the high cost of $\mathrm{ABC}$ consulting guidance was the main motivating factor when deciding to adopt $\mathrm{ABC}$ or not. For firms that had implemented $\mathrm{ABC}$, satisfaction levels were higher because of the benefits created by ABC.

Many researchers have also engaged in a broader question, aside from what does or does not encourage $\mathrm{ABC}$ success, is ABC, as a whole, successful? Some scholars have used the phrase 'the activity based costing paradox' to describe the contradiction in the seeming benefits of $\mathrm{ABC}$ on paper versus the sometimes lacklustre performance after implementation. Dolinsky and Vollmann (1991) have raised concerns that ABC may lead to 
neglect of non-financial performance measures such as quality and costumer service, a concern that is shared by Johnson (1992) and (Swenson, 1995). Many studies have also suffered from vague, qualitative measures of success, such as whether or not ABC data was utilized in decision making (Cotton, 1993; Lukka \& Granlund, 1994; Innes \& Mitchell, 1995; Krumwiede, 1996, 1998), satisfaction of company employees, who may have a personal stake in perceived success (McGowan \& Klammer, 1997; Swenson, 1995; Shields, 1995) and perceived as opposed to empirically measured financial benefit (Shields, 1995; Krumwiede, 1996, 1998; Cagwin \& Bouwman, 2000).

Despite these concerns, a number of studies have succeeded in proving ABC's success by a variety of different measurements. Swenson (1995) showed through a wide-reaching interview process that while the application of $\mathrm{ABC}$ may vary drastically between sectors, every industry could learn how to benefit from at least one aspect of ABC. Cagwin and Bouwman's 2000 study showed that ABC can improve financial performance when implemented correctly, which is also supported by Hoa (2010). Hoa's research found that ABC was vital in improving financial performance of manufacturing firms only when the organization had a thorough understanding of identifying cost drivers and the overall nature of ABC. Maiga and Jacobs (2008) found in a survey of 691 manufacturing plants that the extent of $\mathrm{ABC}$ use is significant correlated to quality improvement, cycle-time improvement and cost improvement. Foster and Swenson (1997) concluded that discrepancies in discussing the effectiveness of ABC often result from differing definitions of success. Dooley (2007) found that using the $\mathrm{ABC}$ method is shown to improve a firm's pricing strategy, CRM, product management and price negotiations / sentences are not interconnected. With Accenture as an example, they reported their overall cost structure could drop as much 3-5\% after implementing ABC methods. Through ABC costing, managers can better tell which activities create value-added and which are ineffective to production, thus allowing them to make improvements in their process. ABC costing can uncover issues in areas such as managing clients and products, the appropriate pricing and discount methods, making the business process more effective and efficient, and the ability to make an accurate costing model based on the supply chain. A study by Ittner et al. (2002) went into further detail about the success metrics of $\mathrm{ABC}$ and found that $\mathrm{ABC}$ is directly related to improvements in cycle time and quality, but only indirectly related to manufacturing cost reductions and stemming from cycle time and quality improvements. They also found that on average, ABC does not have a significant association with return on assets and that the $\mathrm{ABC}$ method has weak association with a firm's accounting "probability" and financial performance, which disagrees with findings from Hoa (2010). While is often thought that ABC guarantees improved efficiency and cost reductions, implementation problems can hinder results. Ittner, Lanen and Larcker did find and agree that using the $\mathrm{ABC}$ method does mean the production of a higher quality products and a higher decrease in cycle time. By looking at manufacturing firms, the researchers found that $\mathrm{ABC}$ and profit depends on how well the $\mathrm{ABC}$ method matches operational characteristics of the firm. Broad-based models for success, specifically those taking into account how ABC data is utilized for decision-making, tend to yield higher rates of ABC success.

Many studies have also begun to investigate the important link between ABC and activity based management, the stage at which information collected via $\mathrm{ABC}$ is used to inform management decisions such as new product development decisions. Partridge and Perren (1998) have argued that the relatively low usage of ABCM reflects a lack of understanding among managers about how ABC can be utilized to improve their decision-making. Narayanan and Sarkar (2002) showed how, when utilized properly, ABCM can be beneficial to a firm, by informing decisions to discontinue products, changes prices, and, to a somewhat lesser extent, discontinue comparably unprofitable customers. Therefore a proper use of $\mathrm{ABC}$ and, as we argue in this paper, a greater dependence on $\mathrm{ABC}$ would make it more cost efficient and under control for those initiatives to be carried out. Hence our first Hypothesis:

H1: the greater the company's dependence on $\mathrm{ABC}$ costing in their new product development processes, the better cost performance for the company.

The relationship between the theory of constraint (TOC) and ABC has seen some research in recent years as well. Quite a few studies have investigated the differences and similarities between the two systems, including Cooper and Slagmulder (1999); Demmy and Talbott (1998); Holmen (1995); Kee (1995); MacArthur (1993); Patterson (1992); Spoede et al. (1994); Yahya-Zadeh (1998); Hall et al. (1997); Campbell et al. (1997). Sheu, Chen and Kovar's (2001) paper concluded that the two main differences between TOC and ABC are the time line that they address and the information that they provide. Regarding the timeline, TOC focuses on the short-term, since it assumes that at least one resource is fixed and unchangeable. ABC allows for a long-term view, in which all costs can ultimately be adjusted. Combining these two views offer obvious advantages, since businesses ultimately need to make choices in both the long and short-term time horizons. Gurses (1999) examined the 
combination of $\mathrm{ABC}$ and $\mathrm{TOC}$ and found that $\mathrm{ABC}$ costs are important in determining the best product mix of a company and that without $\mathrm{ABC}$ and just using overhead labour costs alone, poor decisions can be made regarding producing the optimal product mix. Gurses also found that the use of $\mathrm{ABC}$ and TOC together is the best way to gather accurate information about costs per activity, which allows managers to make more informed decisions. Regarding the information provided, TOC focuses on areas of limited capacity, whereas ABC looks to excess capacity. Once again, integration can be beneficial with TOC helping managers identify bottleneck resources, and $\mathrm{ABC}$ helping them decide how to fix the problem. The conclusion that $\mathrm{ABC}$ is not useful for the long term as supported above is contradicted in a study by Lea and Min (2003), who found that ABC is useful for both short and long term gains. Lea and Kim also found $\mathrm{ABC}$ led to better customer service and lower work-in-progress inventory (WIP). These conclusions were found true only where firms had high overhead costs and low material and labor costs. They also studied the effectiveness of just-in-time (JIT) inventory in comparison with the TOC, and found that JIT outperformed the TOC with short and long term profitability, customer service, and WIP inventory. The accounting methods used should be best suited to the manufacturing process of a business so there can be more accurate cost measurements and better performance. Furthermore, it is important to note that the study found that regardless of the method a firm adopts, the performance of that method will not change for the company over time.

Other studies looked at the TOC in comparison to traditional accounting methods (Utku et al., 2011). Utku et al. (2011) looked at the benefits and downsides to producing the optimal product mix with the TOC compared to traditional costing methods. Specifically, they compared to two methods by measuring the throughput rates, the contribution margin approach and the unit-profit approach. The study found that the firm they monitored had a better understanding of the short-term picture of the overall company, and also that they were able to make more efficient managerial decisions about the product mix for the short-term with the adoption of the TOC. Through the contribution margin analysis, there was no difference between the contribution margin of variable costing or traditional throughput accounting. The full-costing method is necessary for financial reports, but the variable costing approach here is better suited for managers to make decisions. In the variable costing approach, the study found that the TOC method was better at determining the product mix, which defines the optimal mix where one prioritizes the product with the highest throughput rate that takes the least amount of resources. They conclude that using the TOC produces a "more factual product cost" which leads to better short-term decision making. A study by Ifandoudas and Gurd (2010) concludes in conjunction with the work of Utku et al. (2011) about the TOC allowing for better-informed managerial decisions for the short term. This study also explored, however, the impact of the TOC for the long term, since previously the focus was only of TOC and managerial decisions in the short term. The study disagrees with Utku et al. (2011) about implementing TOC and ABC accounting because of the short-term focus. The study also brings up the point that oftentimes people do not want to work with a complex model such as TOC or ABC. They also propose that by focusing on optimization for short-term decisions can mean misleading information for the future. They also see that can be a difficulty with recognizing constraints, which alters with levels of production. Other benefits of TOC are that it ensures that non-vital machines are not running at full capacity if unnecessary. TOC allows the company to recognize weak leadership if a manager wants to utilize specific machines that are not the most optimal process for the organization.

There has also been research done about the TOC and its relation to TQM. TQM is an important process for any supply chain and if a company adapts both TQM and TOC, then they can have both a productive and efficient manufacturing process. However, barriers such as difficulty understanding and resistance to change can affect the adoption of these methods.

Limited research has also been done on the use of costing in firms that are pursuing new product development initiatives. One study (Stump, 2008) that did investigate the matter found that TOC could be useful in cases of mass customization, but only when the level of customization is relatively minimal and pursued only in the assembly and delivery stage. In most cases of mass customization companies must deal with high work content variation that does not lend itself well to TOC, which is designed to work in companies with a static constraint. Stump did suggest however that more research is necessary, as it is possible that TOC could be adjusted to better fit a generic new product development strategy (Stump, 2008). Hence our second hypothesis:

$\mathrm{H} 2$ : the greater the company's dependence on TOC costing in their new product development processes, the better cost performance for the company.

While these topics have been studied to various degrees, this paper seeks to fill a gap in the research, by addressing how both ABC and TOC can be used in to better the cost management of NPD. The answer will guide manufacturers embarking on new product development projects in choosing the best costing strategy for their company. 


\section{Methodology}

To test the two hypotheses we carried out a survey to investigate the impact of TOC and ABC on the new product development cost. A carefully designed questionnaire was prepared through careful study of previous research and then constructs were developed to measure the variables of the study (Al Zu'bi \& Tsinopoulos, 2010). ABC and TOC involvement in the costing of the new product development processes was evaluated by using 8 constructs. The cost performance of the new product development consisted of 4 constructs and asked respondents to rate the costs of the key new product development stages relative to their competition. Several concerns have been expressed for the use of perceptual measures that require respondents to compare themselves against competition The key issues centre on the use of a single informant, which is the case in this study. When relying on only one informant there is a risk of underestimating the true parameters due to dishonesty and/or systematic bias Although it is acknowledged that there is such a risk in this study, and thus this is a potential limitation, any risk of bias has been minimised by ensuring that the questionnaire was answered by the officer in charge of product development activities who is knowledgeable about the costing of the whole process. Then the reliability of the questionnaire was checked using he Cronbach's $\alpha$-values and it was calculated that all items in the questionnaire ranged from 0.85 to 0.95 , indicating that there was internal consistency between the items, and confirming the reliability of the constructs employed.

\section{Data Collection}

The companies that were surveyed in this study were European manufacturers with a record of initiatives in new product development. 400 companies were randomly contacted from the directory of the European manufacturers. These companies represented a variety of industries ranging from health care products, to motor makers. 204 usable questionnaires were returned. This corresponds to a response rate of 51\%, which is considered to be an acceptable rate for such studies.

The hypotheses presented above examine the relationships between ABC and TOC and the new product development costs, there are some contextual factors that could affect this relationship and must therefore be controlled for; a regression model was constructed for this reason as follows:

$$
C A V=\beta 0+\beta 1 F S+\beta 2 F A+\beta 3 T O C A V+\beta 4 I N P D+\beta 5 A B C A V+\varepsilon
$$

Where: CAV: Product Development Cost,

$\beta 0$ : Constant,

$\beta 1, \beta 2, \beta 3, \beta 4$ and $\beta 5$ : Coefficients,

FS: Firm size,

FA: Firm age,

TOCAV: Theory of Constraint costing,

ABCAV: ABC costing, and

$\varepsilon$ : error

\section{Results}

This study encompassed a range of companies and industries. The sample varied in the size and age. Companies ranged in size from small (less than two hundred and fifty employees) to large (more than a thousand employees), with most companies being of intermediate size. Most of the companies (50\%) were more than 20 years old, and the rest of the categories were normally distributed.

The New product development processes were used previously as a construct in (Al-Zu'bi \& Tsinopoulos, 2010) and it was properly validated and tested. This model was tested using hierarchical regression analysis of the summated scores of the independent and control variables on NPD cost. The results shown in Table 1 indicate a significant statistical association between TOC and NPD costs and also ABC and NPD costs. This lends support to the first and second hypotheses, which predicted that increased TOC would lead to better-cost control of NPD and also increased $\mathrm{ABC}$ would reduce costs. The control variables showed no significant association, which supports the generalizability of this model across the different companies. The $\mathrm{R}^{2}$ value of the model is satisfactory and the ANOVA test of the model indicates high significance $(p=0.000)$, confirming that this model has statistical strength to explain the relationship. 
Table 1. Hierarchical regression model: dependent variable NPD costs model summary

Panel A.

\begin{tabular}{ccccc}
\hline Model & $\mathbf{R}$ & $\mathbf{R}^{\mathbf{2}}$ & Adjusted $^{\mathbf{2}}$ & Std. Error of the Estimate \\
\hline 1 & $.209^{\mathrm{a}}$ & .044 & .034 & .78909 \\
2 & $.406^{\mathrm{b}}$ & .165 & .148 & .74117 \\
\hline
\end{tabular}

Note. a. Predictors: (Constant), age of the company by years, Company Size.

b. Predictors: (Constant), age of the company by years, Company Size, TOCAV, ABCAV.

Panel B. ANOVA ${ }^{\mathrm{c}}$

\begin{tabular}{lllllll}
\hline Model & Sum of Squares & df & Mean Square & F & Sig. \\
\hline \multirow{2}{*}{1} & Regression & 5.73 & 2 & 2.87 & 4.6 & $.011^{\mathrm{a}}$ \\
& Residual & 125.15 & 201 & .62 & & \\
& Total & 130.89 & 203 & & & \\
& Regression & 21.57 & 4 & 5.39 & 9.8 & $.000^{\mathrm{b}}$ \\
2 & Residual & 109.32 & 199 & .55 & & \\
& Total & 130.89 & 203 & & & \\
\hline
\end{tabular}

Note. a. Predictors: (Constant), age of the company by years, Company Size;

b. Predictors: (Constant), age of the company by years, Company Size, TOCAV, ABCAV;

c. Dependent Variable: CAV.

Panel C. Continued: Coefficients ${ }^{\mathrm{a}}$

\begin{tabular}{|c|c|c|c|c|c|c|}
\hline \multirow{2}{*}{\multicolumn{2}{|c|}{ Model }} & \multicolumn{2}{|c|}{ Unstandardized Coefficients } & \multirow{2}{*}{ Beta } & \multirow{2}{*}{$\mathbf{t}$} & \multirow{2}{*}{ Sig. } \\
\hline & & $\mathrm{B}$ & Std. Error & & & \\
\hline \multirow{3}{*}{1} & (Constant) & 3.341 & .157 & & 21.337 & .000 \\
\hline & Company Size & .000 & .000 & .175 & 2.534 & .012 \\
\hline & age of the company by years & -.006 & .003 & -.121 & -1.750 & .082 \\
\hline \multirow{5}{*}{2} & (Constant) & 2.190 & .264 & & 8.309 & .000 \\
\hline & Company Size & .000 & .000 & .124 & 1.883 & .061 \\
\hline & age of the company by years & .000 & .003 & -.017 & -.246 & .806 \\
\hline & TOCAV & .119 & .062 & .134 & 1.931 & .055 \\
\hline & ABCAV & .232 & .056 & .300 & 4.180 & .000 \\
\hline
\end{tabular}

Note. a. Dependent Variable: CAV.

From the analysis in the tables we can notice that $\mathrm{ABC}$ has a stronger relationship with a standardized beta of $30 \%$, whereas TOC has only $13 \%$. This is supported by the $\mathrm{R}^{2}$ of the model which has increased by $12 \%$ indicating a statistical ability in explaining the variance caused.

\section{Discussion and Conclusions}

In our paper we sought to provide evidence about the effect of costing technique used by companies on the cost performance of new product development initiatives in industrial companies in Europe. Using data from 204 European manufacturers, we found that using the $\mathrm{ABC}$ technique would reduce cost more than what can be achieved by TOC. Although it is important not to overstate these findings, as NPD costs depend on many contextual factors both external and internal to the organisation, they add further support to the benefits of $\mathrm{ABC}$ usage in the costing of NPD.

This work emphasises the importance of $\mathrm{ABC}$, however, the findings do not preclude the value of other costing techniques in reducing production cost, nor do they prove that TOC should be abandoned. Our results help manufacturers to explain some of the differences found in the literature in relation to the overall benefits of different costing techniques.

Therefore, companies should place more emphasis on the use of ABC rather than relying on the use of TOC. However there have been some limitations that need to be mentioned for this work to be more rigor; the first is the use of perceptual measures of our variables, as discussed above. Although we have taken several steps to 
ensure that the concepts used in this study are accurate, there is some scope for error in the measurement process. A second limitation is the use of single informant. Again, we have taken several steps to reduce any possible impact of this on our results, but as has been reported in other similar studies, we cannot guarantee that this has not affected our results. Our final limitation relates to the inclusion of other factors that may also affect costs. Although we have found no statistical significance between development costs and the other variables studied, there may be other contextual factors that may also explain some of the variance, for instance, the type of industry, or the type of the new product development initiatives amongst others.

\section{References}

Al-Basteki, H., \& Ramadan, S. (1998). A Survey of Activity-Based Costing Practices in Bahraini Manufacturing Firms. JKAU: Econ. \& Adm, 11, 17-29.

Al-Zu'bi, Z. M. F., \& Tsinopoulos, C. (2012). Suppliers versus Lead Users; Examining their relative impact on product variety. Journal of Product Innovation Management, 26(4), 667-680. http://dx.doi.org/10.1111/j.1540-5885.2012.00932.x

Anderson, S. W. (1995). A framework for assessing cost management system changes: the case of activity-based costing implementation at general motors 1986-1993. Journal of Management Accounting Research, 7, 151 .

Anderson, S. W., \& Young, S. M. (1999). The impact of contextual and process factors on the evaluation of activity-based costing systems. Accounting, Organizations and Society, 24, 525-559. http://dx.doi.org/10.1016/S0361-3682(99)00018-5

Argyris, C., \& Kaplan, R. S. (1994). Implementing new knowledge: the case of ABC. Accounting Horizons, 8, $83-105$.

Armitage, H. M., \& Nicholson, R. N. (1993). Activity-Based Costing. The Society of Management Accountants of Canada, Management Accounting Issues Paper 3, Hamilton, Ontario.

Armstrong, P. (2002). The costs of activity-based management. Accounting, Organizations and Society, 27, 98120. http://dx.doi.org/10.1016/S0361-3682(99)00031-8

Babad, Y. M., \& Balachandran, B. V. (1993). Cost driver optimization in activity-based costing. The Accounting Review, 68, 563-564.

Bhimani, A., \& Pigott, D. (1992). Implementing ABCM: a case study of organizational and behavioural consequences. Management Accounting Research, $119-132$. http://dx.doi.org/10.1016/S1044-5005(92)70007-9

Bhimani, A., Gosselin, M., \& Ncube, M. (2005). Strategy and activity based costing: a cross-national study of process and outcome contingencies. International Journal of Accounting, Auditing and Performance Evaluation, 2(3). http://dx.doi.org/10.1504/IJAAPE.2005.007672

Bjornenak, T. (1997). Diffusion and accounting: the case of ABCM in Norway. Management Accounting Research, 8, 3-17. http://dx.doi.org/10.1006/mare.1996.0031

Cagwin, D., \& Bouwman, M. (2000). The Association between activity-based costing and improvement in financial performance. Management Accounting Research, 13(1), 1-39. http://dx.doi.org/10.1006/mare.2001.0175

Campbell, R., Brewer, P., \& Mills, T. (1997). Designing an information system using activity-based costing and the theory of constraints. Management Accounting, 16-25.

Cooper, R., \& Slagmulder, R. (1999). Integrating ABC and TOC. Management Accounting, 20-21.

Cooper, R. B., \& Zmud, R. W. (1990). Information technology implementation research: A technological diffusion approach. Management Science, 36(2), 123-139. http://dx.doi.org/10.1287/mnsc.36.2.123

Cotton, W. D. J. (1993). Activity-Based Costing in New Zealand. Working Paper. SUNY at Genesco.

Demmy, S., \& Talbott, J. (1998). Improve internal reporting with ABC and TOC. Management Accounting, 1824.

Dolinsky, L. R., \& Vollmann, T. E. (1991). Transaction-based overhead considerations for product design. Journal of Cost Management, 7-19.

Dooley, B. (2007). Using Activity Based Costing Techniques to Drive Supply Chain Process Improvement and Business Profitability. Supply Chain Europe, 16(2), 32-35. 
Drury, C., \& Tayles, M. (1994). Product costing in UK manufacturing organizations. European Accounting Review, 3, 443-469. http://dx.doi.org/10.1080/09638189400000031

Foster, G., \& Swenson, D. (1997). Measuring the success of activity-based costing management and its determinants. Journal of Management Accounting Research, 9, 109-141.

Friedman, A., \& Lyne, S. (1999). Measuring the success of activity-based costing management and its determinants. Journal of Management Accounting Research, 9, 109-141.

Gordon, L., \& Silvester, K. (1999). Stock market reactions to activity based costing adoptions. Journal of Accounting and Public Policy, 18, 229-251. http://dx.doi.org/10.1016/S0278-4254(99)00009-5

Gosselin, M. (1997). The effect of strategy and organizational structure on the adoption and implementation on activity-based costing. Accounting, Organizations and Society, 22, $105-112$. http://dx.doi.org/10.1016/S0361-3682(96)00031-1

Gurses, A. P. (1999). An Activity-Based Costing and Theory of Constraints Model for Product-Mix Decisions. Master of Science Thesis. Blacksburg, Virginia.

Hall, R., Galambos, N. P., \& Karlsson, M. (1997). Constraint-based profitability analysis: stepping beyond the theory of constraints. Journal of Cost Management, 6-10.

Harper, W. M. (1995). Cost and Management Accounting. London: FT Pitman Publishing.

Hoa, N. T. (2010). The Impact and Importance of Activity Based Costing on Financial Performance of Manufacturing Firm. Graduation Project, HELP University College.

Holmen, J. S. (1995). ABC vs. TOC: it's a matter of time. Management Accounting, 76, 37-40.

Ifandoudas, P., \& Gurd, B. (2010). Costing for Decision-Making in a Theory of Constraints Environment. JAMAR, 8(1), 43-58.

Innes, J., \& Mitchell, F. (1995). A Survey of Activity-Based Costing in the U.K.'s Largest Companies. Management Accounting Research, 137-153. http://dx.doi.org/10.1006/mare.1995.1008

Innes, J., Mitchell, F., \& Sinclair, D. (2000). Activity-based Costing in the UK's Largest Companies: A Comparison of 1994 and 1999. Survey Results, 11(3), 349-362.

Ittner, C. D., Lanen, W. N., \& Larcker, D. F. (2002). The association between Activity Based Costing and manufacturing performance. Journal of Accounting Research, 40(3), 711-726. http://dx.doi.org/10.1111/1475-679X.00068

Johnson, H. T. (1992). Its time to stop overselling activity-based concepts. Management Accounting, 26-35.

Jones, C. T., \& Dugdale, D. (2002). The ABC bandwagon and the juggernaut of modernity. Accounting, Organizations and Society, 27, 121-164. http://dx.doi.org/10.1016/S0361-3682(01)00035-6

Kee, R. (1995). Integrating activity-based costing with the theory of constraints to enhance production-related decision-making. Accounting Horizons, 9(December), 48-61.

Kennedy, T., \& Affleck-Graves, J. (2001). The impact of activity based costing techniques on firm performance. Journal of Management Accounting Research, 13, 19-46. http://dx.doi.org/10.2308/jmar.2001.13.1.19

Krumwiede, K. R. (1996). An Empirical Examination of Factors Affecting the Adoption of Activity Based Costing. Dissertation. University of Tennessee.

Krumwiede, K. R. (1998). The implementation stages of activity-based costing techniques on firm performance. Journal of Management Accounting Research, 13, 19-46.

Kwon, T. H., \& Zmud, R. W. (1987). Unifying the fragmented models of information systems implementation. In R. J. Boland \& R. Hirscheim (Eds.), Critical Issues in Information Systems Research. New York, NY: John Wiley.

Lea, B., \& Min, H. (2003). Selection of Management Accounting Systems in Just-In-Time and Theory of Constraints-Based Manufacturing. INT. J. PROD. RES, 41(13), 2879-2910. http://dx.doi.org/10.1080/0020754031000109134

Lukka, K., \& Grandlund, M. (1994). Cost Accounting Practice in Finland. Working Paper. Turku School of Economics and Business Administration, Finland.

MacArthur, J. B. (1993). Theory of constraints and activity-based costing: friends or foes? Journal of Cost Management, 50-56. 
Maiga, A., \& Jacobs, F. (2008). Extent of ABC Use and Its Consequences. Contemporary Accounting Research, 25(2), 553-566. http://dx.doi.org/10.1506/car.25.2.9

Malmi, T. (1999). Activity-based costing diffusion across organizations: an exploratory empirical analysis of Finnish firms. Accounting, Organizations and Society, 20, 137-150.

McGown, A. S., \& Klammer, T. P. (1997). Satisfaction with activity-based cost management. Journal of Management Accounting Research, 9, 217-238.

Narayanan, V. G., \& Sarkar, R. (2002). The Impact of Activity-based costing on managerial decisions at insteel industries-a field study. Journal of Economics and Management Strategy, 11(2), 257-288. http://dx.doi.org/10.1162/105864002317474567

Nassar, M., Al-Khadash, H., Sangester, A., \& Mah'd, O. (2013). Factors that Catalyse, Facilitate and Motivate the Decision to Implement Activity-Based Costing in Jordanian Industrial Companies. Journal of Applied Accounting Research, 14(1), 18-36. http://dx.doi.org/10.1108/09675421311282522

Patridge, M., \& Perren, L. (1998). An integrated framework for activity-based decision making. Management Decision, 36(9), 580-588. http://dx.doi.org/10.1108/00251749810239469

Patterson, C. M. (1992). The product-mix decision: a comparison of TOC and ABC. Production and Inventory Management Journal, 3, 80-85.

Sheu, C., Chen, M. H., \& Kovar, S. (2003). Integrating ABC and TOC for better manufacturing decision making. Integrated Manufacturing Systems, 14(5), 433-441. http://dx.doi.org/10.1108/09576060310477834

Shields, M. (1995). An Empirical Analysis of Firms' Implementation Experiences with Activity-Based Costing. JMAR, 7(Fall).

Shields, M., \& Young, S. M. (1989). A Behavioural Model for Implementing Cost Management Systems. Journal of Cost Management, Winter, 17-27.

Shields, M., \& Young, S. M. (1994). Behavioural and organizational issues. In B. Brinker (Ed.), Handbook of Cost Management. New York: Warren Gorham Lamont.

Sisaye, S. (2003). Process innovation and adaptive institutional change strategies in management control systems: $\mathrm{ABC}$ as administrative innovation. Advances in Management Accounting, 11, 251-286. http://dx.doi.org/10.1016/S1474-7871(02)11011-2

Spoede, C., Henke, E. O., \& Umbele, M. (1994). Using activity analysis to located profitability drivers: ABC can support a theory of constraints management process. Management Accounting, 43-48.

Stump, G. B. (2008). An Integrated Framework for Applying Lean Manufacturing and Other Strategies in Mass Customization Environments. University of Kentucky.

Swenson, D. (1995). The Benefits of Activity-Based Cost Management to the Manufacturing Industry. JMAR, 7(Fall).

Utku, B. D., Cengiz, E., \& Ersoy, A. (2011). Comparison of the Theory of Constraints with the Traditional Cost Accounting Methods in Respect to Product Mix Decisions. Dogus University Dergisi, 12(2), 317-331.

Yahya-Zadeh, M. (1998). Product-mix decisions under activity-based costing with resource constraints and non-proportional activity costs. Journal of Applied Business Research, 39-45.

\section{Copyrights}

Copyright for this article is retained by the author(s), with first publication rights granted to the journal.

This is an open-access article distributed under the terms and conditions of the Creative Commons Attribution license (http://creativecommons.org/licenses/by/3.0/). 